\title{
Hamster Pituitary Carcinoma
}

National Cancer Institute

\section{Source}

National Cancer Institute. Hamster Pituitary Carcinoma. NCI Thesaurus. Code C134993.

Carcinoma arising in the pituitary gland and occurring in a hamster. 